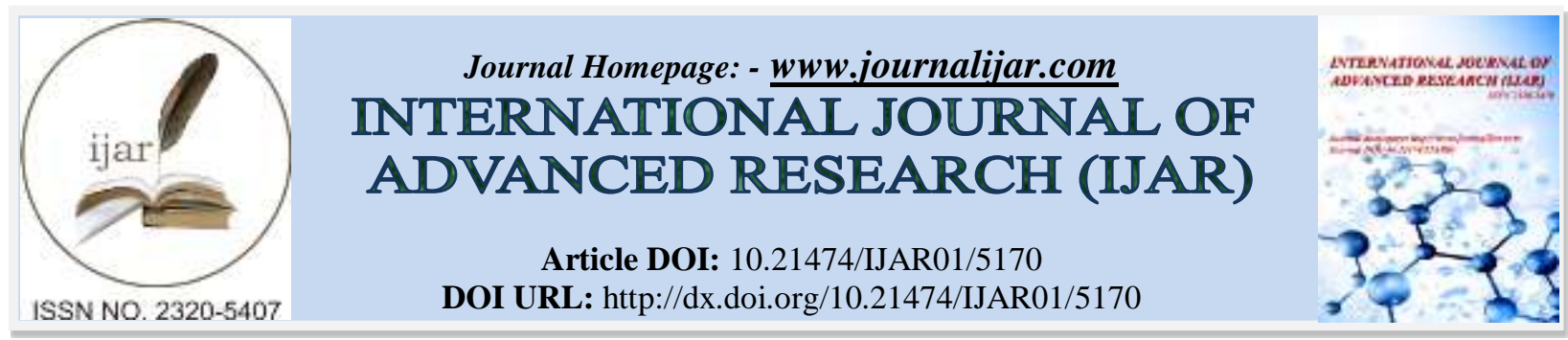

RESEARCH ARTICLE

\title{
PREVALENCE AND FACTORS ASSOCIATED WITH FUNCTIONAL CONSTIPATION AMONG CHILDREN ATTENDING WELL BABY CLINIC IN ALADEL PRIMARY HEALTH CARE CENTER IN MAKKAH AL-MUKARRAMAH, 2016, CROSS SECTIONAL.
}

1. MBBS, Family Medicine Resident.

Maha AlGhamdi ${ }^{1}$ and Abduljabbar Alfetni ${ }^{2}$.

2. Family medicine consultant.

\section{Manuscript Info}

Manuscript History

Received: 14 June 2017

Final Accepted: 16 July 2017

Published: August 2017

Key words:-

Functional constipation, Children, Rome

III criteria, well baby clinic.

\section{Abstract}

Objectives: To estimate the prevalence and determine associated factors of functional constipation among children attending well baby clinic in AlAdel primary health care center in Makkah 2016.

Methodology: A cross-sectional study was done including 80 child aged five years or less. Data was collected by interviewing children's mothers and filling a questionnaire that depends on Rome III criteria for identification of functional constipation.

Results: The children mean age was $20 \pm 17.7$ months. The prevalence of functional constipation diagnosed according to Rome III criteria was $22.5 \%$ (95\% CI $13.8-31.3)$. The most common reported symptoms were painful defecation $(83.3 \%)$ and hard to very hard stool $(77.8 \%)$, followed by Stool frequency 2 times or less per week (44.4\%), large stools that obstruct the toilet ( $22.2 \%$ ), stool retention once per week or more $(33.3 \%)$, large fecal mass in the rectum $(16.7 \%)$ and Soiling (one to three times a month, which does not meet Rome III criteria) was reported by $11.1 \%$ of children with functional constipation. All mothers aged 19 years or less compared to $20.5 \%$ of those aged over 19 years had children with functional constipation $(\mathrm{p}=0.048)$. Children on bottle feeding expressed higher rate of functional constipation compared to those on breast or mixed feeding $(38.5 \%$ versus $4.8 \%$ and $21.2 \%$, respectively), $(\mathrm{p}=0.022)$. Having no serving fruits provided daily was associated with significant higher rate of functional constipation compared to having more than one cup of serving fruits provided daily (55.6\% versus $12.2 \%),(\mathrm{p}=0.020)$. Anal fissure was more significantly reported among children with functional constipation compared to those without functional constipation ( $11.1 \%$ versus none), $(\mathrm{p}=0.008)$.

Conclusion: Functional constipation is not uncommon gastrointestinal disturbance among children aged five years or less attending AlAdel primary health care center in Makkah with few socio-demographic and dietary risk factors were identified. 


\section{Introduction:-}

Bowel movement pattern is an indicator of child's health for all ages. In first few weeks of life, normal infants pass four liquid bowel movements and in the first three months of life, infants have about three bowel movements (breast fed infant will have bowel movements that are more frequent). By two years, a child will have one to two formed bowel movements ${ }^{(1)}$. Parents may complain of that their child pass infrequent stool or hard stool, straining during defecation, has painful bowel movement or stool incontinence. Constipation is a symptom not a disease. The term derived from Latin word (constipare) which mean crowd together ${ }^{(2)}$. One of the key problems in studying constipation is subjective nature of this symptom that makes a challenge in definition and diagnosis of childhood constipation. Therefore, Rome III criteria were developed in 2006 to standardize the definition of childhood constipation as:

\section{Functional constipation:-}

Must include one month of at least two of the following in infants up to four years of age:

- Two or fewer defecations per week.

- At least one episode per week of incontinence after the acquisition of toileting skills.

- History of excessive stool retention.

- History of painful or hard bowel movements.

- Presence of a large faecal mass in the rectum.

- History of large-diameter stools that may obstruct the toilet.

Must include two or more of the following in a child with a developmental age of at least four years with insufficient criteria for diagnosis of irritable bowel syndrome:

- Two or fewer defecations in the toilet per week.

- At least one episode of faecal incontinence per week.

- History of retentive posturing or excessive volitional stool retention.

- History of painful or hard bowel movements.

- Presence of a large faecal mass in the rectum.

- History of large-diameter stools that may obstruct the toilet.

Criteria must be fulfilled at least once per week for at least 2 months before diagnosis ${ }^{(2)}$.

The prevalence of constipation in children internationally is about $30 \%{ }^{(2)}$ and no difference found between boys and girls ${ }^{(3)}$.Approach to constipated child relies on clinical history and physical examination to exclude organic causes. Functional constipation is the cause of constipation in the majority of children ${ }^{(4)(5)}$. Previous history of painful defecation is a common participant of constipation in children ${ }^{(6)}$. When children experience pain during defecation they will avoid it by toilet refusal which leads to distension of the rectum that eventually leads to ignorance of signals from rectum to the brain result in large, hard stool that is difficult to pass which result in constipation cycle. Also, low fibers intake play a role in constipation ${ }^{(7)}$. It is a common problem and has adverse effects on child physically and psychosocially because children who have chronic constipation will have impaired quality of life ${ }^{(8)}$ and are at more risk for developing anal fissures, abdominal pain, fecal incontinence ${ }^{(2)}$, urinary incontinence and urinary tract infection ${ }^{(9)}$.

\section{Objectives:-}

1) To estimate the prevalence of functional constipation among children attending well baby clinic in AlAdel primary health care center in Makkah 2016.

2) To determine factors associated with functional constipation among children attending well baby clinic in AlAdel primary health care center in Makkah 2016.

\section{Methodology:-}

A cross-sectional study was conducted among children (males and females) aged 5 years or less attending well baby clinic in AlAdel PHCC in Makkah Almukarrmah constituted the study population.

A self-constructed questionnaire designed to collect the desired data. It consists of four parts: 1. Socio-demographic data. 2. Identifying children with constipation using Rome III criteria. 3. Children's nutritional history

4. Outcomes of functional constipation. 
The questionnaire was filled by interviewing the mothers (face to face) in the waiting area after obtaining verbal consent from each mother. This study was done over one month period.

Data entry and statistical analysis were performed using the Statistical package for social sciences (SPSS) program, version 22. Frequency and percentage were used for the description of categorical variables whereas arithmetic mean and standard deviation (SD) were used for the description of continuous variables. Chi square test was applied to test for the association and/or difference between two categorical variables whereas Fishcer Exact test was applied for small frequencies instead of chi-square test. Shapiro Wilk test was utilized to test for normality of continuous variables. Child `s age was abnormally distributed, $p<0.001$. Mann-Whitney test was used to compare the age of children according to functional constipation. Significance was identified at $p-v a l u e<0.05$.

\section{Results:-}

\section{Socio-demographic characteristics:-}

The study included 80 children, out of targeted 80 , giving a response rate of $100 \%$. Table 1 summarizes the sociodemographic characteristics of the children and their mothers. Age of children ranged between one month and five years with a mean \pm SD of $20 \pm 17.7$ months. Slightly more than half of them (53.7\%) were females. All were Saudis. Number of siblings ranged between one and three among almost two-thirds of them (62.5\%). Regarding their mothers` characteristics, majority of them (97.5\%) aged over 19 years. More than half of them $(52.5 \%)$ were at least university graduated. Most of them (73.7\%) were house wives whereas $17.5 \%$ were workers in the health sector.

\section{Functional constipation:-}

Eighteen children were diagnosed with Functional constipation according to Rome III criteria. The prevalence of functional constipation was $22.5 \%$ ( 95\% CI 13.8 - 31.3) of the respondents as illustrated in figure 1. Among them, stool frequency was 2 times or less per week among $44.4 \%$ and hard to very hard stool was reported by majority of cases $(77.8 \%)$. Painful defecation and large stools that obstruct the toilet were reported among $83.3 \%$ and $22.2 \%$ of cases, respectively. Stool retention (once per week or more) was reported among 33.3\% of children with functional constipation whereas large fecal mass in the rectum was observed among $16.7 \%$ of them. Soiling (one to three times a month, which does not meet Rome III criteria) was reported by $11.1 \%$ of children with functional constipation. (Table 2 \& Figures $1 \& 2$ )

\section{Children`s nutritional history:-}

Natural breast feeding was reported among $26.3 \%$ of the children whereas bottle or mixed feeding were reported by $32.5 \%$ and $41.2 \%$ of them, respectively. Introducing solid food was mentioned by about two-thirds of them (63.7\%); mostly at the age of 4-6 months (60.8\%). None of the cases had solid food introduced before 4 months of age. Among those who reported introducing solid food, the amount of serving fruits provided daily was one cup in 58.8\% of them, the amount of serving vegetables provided daily was one cup in $35.3 \%$ and $55 \%$ always have enough amount of water daily.

\section{Factors associated with functional constipation:-}

-Socio-demographic factors:

Table 3 shows that all mothers aged 19 years or less compared to $20.5 \%$ of those aged over 19 years had children with functional constipation, $\mathrm{p}=0.048$, making mother's age 19 years or less significantly associated with having a child with functional constipation. Other socio-demographic characteristics of children (gender, age and number of siblings) and their mothers (educational level and job status) were not significantly associated with functional constipation.

-Nutritional factors:

Children on bottle feeding expressed higher rate of functional constipation compared to those on breast or mixed feeding (38.5\% versus $4.8 \%$ and $21.2 \%$, respectively), $\mathrm{p}=0.022$. Having no serving fruits provided daily was associated with significant higher rate of functional constipation compared to having more than one cup of serving fruits provided daily $(55.6 \%$ versus $12.2 \%$ ), $\mathrm{p}=0.020$. Other studied nutritional factors (age at introducing of solid food, amount of serving vegetables provided daily and having enough amount of water daily) were not significantly associated with functional constipation. (Table 4) 


\section{Outcomes:-}

Abdominal pain history was reported by a quarter of the children (25\%); its duration was 6 months or less among $45 \%$ of cases while it exceeded 12 months among $35 \%$ of them (figure 3). Anal fissure was reported by two children $(2.5 \%)$. The duration of anal fissure was one month in one case and 36 months in the other one. Urinary tract infection was reported by three cases (3.8\%), the duration of UTI in one case was two months and in the other two cases, it was 24 months.

Among toilet trained children $(\mathrm{n}=16), 50 \%$ and $25 \%$ had urinary and stool incontinence, respectively. The duration of urinary incontinence was 12 months or less among $62.5 \%$ of the children (figure 4). The duration of stool incontinence among the affected 4 cases was one month in two cases, 4 months in one case and 8 months in the last one.

As illustrated in table 5, anal fissure was more significantly reported among children with functional constipation compared to those without functional constipation ( $11.1 \%$ versus none), $\mathrm{p}=0.008$. Similarly, abdominal pain, urinary tract infection, urinary and stool incontinence were more reported among children with functional constipation than those without functional constipation. However, the differences were not statistically significant.

Table 1:- Socio-demographic characteristics of the children and their mothers $(n=80)$

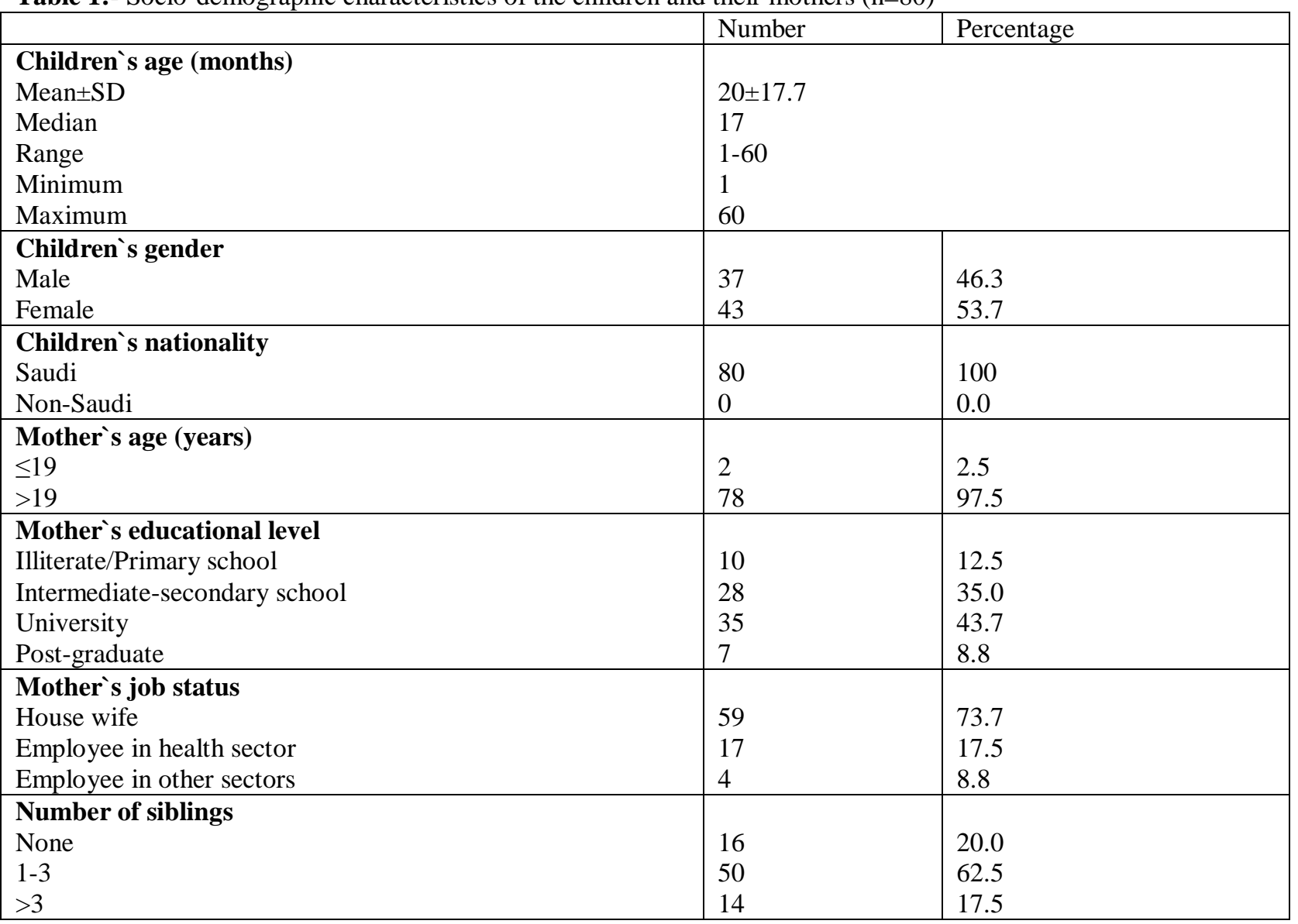

Table 2:- Frequency of Rome III criteria for functional constipation $(n=18)$

\begin{tabular}{|l|l|l|}
\hline & Frequency & Percentage \\
\hline Stool frequency & & \\
$\leq 2$ times a week & 8 & 44.4 \\
$>2$ times a week & 10 & 55.6 \\
\hline $\begin{array}{l}\text { Stool consistency } \\
\text { Very hard }\end{array}$ & 5 & \\
\hline
\end{tabular}




\begin{tabular}{|c|c|c|}
\hline $\begin{array}{l}\text { Hard } \\
\text { Not too hard and not too soft } \\
\text { Not always the same in consistency }\end{array}$ & $\begin{array}{l}9 \\
3 \\
1\end{array}$ & $\begin{array}{l}50.0 \\
16.7 \\
5.6\end{array}$ \\
\hline $\begin{array}{l}\text { Painful defecation } \\
\text { Yes } \\
\text { No }\end{array}$ & $\begin{array}{l}15 \\
3\end{array}$ & $\begin{array}{l}83.3 \\
16.7\end{array}$ \\
\hline $\begin{array}{l}\text { Large stools that obstruct the toilet } \\
\text { Yes } \\
\text { No }\end{array}$ & $\begin{array}{l}4 \\
14\end{array}$ & $\begin{array}{l}22.2 \\
77.8\end{array}$ \\
\hline $\begin{array}{l}\text { Stool retention } \\
\text { Yes, once/week } \\
\text { Yes, several times/week } \\
\text { No }\end{array}$ & $\begin{array}{l}2 \\
4 \\
12\end{array}$ & $\begin{array}{l}11.1 \\
22.2 \\
66.6\end{array}$ \\
\hline $\begin{array}{l}\text { Large fecal mass in the rectum } \\
\text { Yes } \\
\text { No }\end{array}$ & $\begin{array}{l}3 \\
15 \\
\end{array}$ & $\begin{array}{l}16.7 \\
83.3\end{array}$ \\
\hline $\begin{array}{l}\text { Soiling } \\
\text { Yes, 1-3 times/month } \\
\text { No }\end{array}$ & $\begin{array}{l}2 \\
16 \\
\end{array}$ & $\begin{array}{l}11.1 \\
88.8\end{array}$ \\
\hline
\end{tabular}

Table 3:- Socio-demographic factors associated with functional constipation

\begin{tabular}{|c|c|c|c|c|}
\hline \multirow[t]{2}{*}{ Socio-demographic factors } & \multicolumn{2}{|c|}{ Functional constipation } & \multirow[t]{2}{*}{$\chi^{2}$} & \multirow[t]{2}{*}{ p-value } \\
\hline & $\begin{array}{l}\text { No } \\
\text { N=62 } \\
\text { N (\%) }\end{array}$ & $\begin{array}{l}\text { Yes } \\
\mathrm{N}=18 \\
\mathrm{~N}(\%)\end{array}$ & & \\
\hline $\begin{array}{l}\text { Children`s gender } \\
\text { Male }(\mathrm{n}=37) \\
\text { Female }(\mathrm{n}=43)\end{array}$ & $\begin{array}{l}26(70.3) \\
36(83.7)\end{array}$ & $\begin{array}{l}11(29.7) \\
7(16.3)\end{array}$ & 2.06 & 0.151 \\
\hline $\begin{array}{l}\text { Mother`s age (years) } \\
\leq 19(\mathrm{n}=2) \\
>19(\mathrm{n}=78)\end{array}$ & $\begin{array}{l}0(0.0) \\
62(79.5)\end{array}$ & $\begin{array}{l}2(100) \\
16(20.5)\end{array}$ & $0.048 *$ & \\
\hline $\begin{array}{l}\text { Mother`s educational level } \\
\text { Illiterate/Primary school }(\mathrm{n}=10) \\
\text { Intermediate-secondary school }(\mathrm{n}=28) \\
\text { University }(\mathrm{n}=35) \\
\text { Post-graduate }(\mathrm{n}=7)\end{array}$ & $\begin{array}{l}8(80.0) \\
21(75.0) \\
27(77.1) \\
6(85.7)\end{array}$ & $\begin{array}{l}2(20.0) \\
7(25.0) \\
8(22.9) \\
1(14.3) \\
\end{array}$ & 0.41 & 0.938 \\
\hline $\begin{array}{l}\text { Mother`s job status } \\
\text { House wife }(\mathrm{n}=59) \\
\text { Employee in health sector }(\mathrm{n}=14) \\
\text { Employee in other sectors }(\mathrm{n}=7)\end{array}$ & $\begin{array}{l}45(76.3) \\
11(78.6) \\
6(85.7)\end{array}$ & $\begin{array}{l}14(23.7) \\
3(21.4) \\
1(14.3)\end{array}$ & 0.33 & 0.847 \\
\hline $\begin{array}{l}\text { Number of siblings } \\
\text { None }(\mathrm{n}=16) \\
1-3(\mathrm{n}=50) \\
>3(\mathrm{n}=14)\end{array}$ & $\begin{array}{l}11(68.8) \\
40(80.0) \\
11(78.6)\end{array}$ & $\begin{array}{l}5(31.3) \\
10(20.0) \\
3(21.4)\end{array}$ & 0.89 & 0.641 \\
\hline $\begin{array}{l}\text { Children`s age (months) } \\
\text { Mean } \pm \text { SD } \\
\text { Median } \\
\text { Range } \\
\text { Minimum } \\
\text { Maximum } \\
\text { IQR }\end{array}$ & $\begin{array}{l}18.9 \pm 17.5 \\
13.5 \\
1-60 \\
1 \\
60 \\
5-26.75\end{array}$ & $\begin{array}{l}23.6 \pm 18.4 \\
18.5 \\
1-60 \\
1 \\
60 \\
9-36\end{array}$ & $0.244 * *$ & \\
\hline
\end{tabular}

$*$ p-value of Fischer exact test $\quad$ ** p-value of Mann-Whitney-test $\quad$ IQR: Inter-quartile range 
Table 4:- Nutritional factors associated with functional constipation

\begin{tabular}{|c|c|c|c|c|}
\hline & \multicolumn{2}{|c|}{ Functional constipation } & \multirow[t]{2}{*}{$\chi^{2}$} & \multirow[t]{2}{*}{ p-value } \\
\hline & $\begin{array}{l}\mathrm{No} \\
\mathrm{N}=62 \\
\mathrm{~N}(\%)\end{array}$ & $\begin{array}{l}\text { Yes } \\
\mathrm{N}=18 \\
\mathrm{~N}(\%)\end{array}$ & & \\
\hline $\begin{array}{l}\text { Type of feeding } \\
\text { Breast }(n=21) \\
\text { Bottle }(n=26) \\
\text { Mixed }(n=33)\end{array}$ & $\begin{array}{l}20(95.2) \\
16(61.5) \\
26(78.8)\end{array}$ & $\begin{array}{l}1(4.8) \\
10(38.5) \\
7(21.2)\end{array}$ & 7.62 & 0.022 \\
\hline $\begin{array}{l}\text { Introducing solid food } \\
\text { No }(n=29) \\
\text { Yes }(n=51)\end{array}$ & $\begin{array}{l}23(79.3) \\
39(76.5)\end{array}$ & $\begin{array}{l}6(20.7) \\
12(23.5)\end{array}$ & 0.09 & 0.770 \\
\hline $\begin{array}{l}\text { Age at introducing solid food (months) }(\mathbf{n}=\mathbf{5 1}) \\
4-6(\mathrm{n}=31) \\
>6(\mathrm{n}=20)\end{array}$ & $\begin{array}{l}23(74.2) \\
16(80.0)\end{array}$ & $\begin{array}{l}8(25.8) \\
4(20.0)\end{array}$ & $0.450 *$ & \\
\hline $\begin{array}{l}\text { Amount of serving fruits provided daily }(\mathbf{n}=\mathbf{4 7}) \\
\text { Nothing }(\mathrm{n}=9) \\
\text { One cup }(\mathrm{n}=30 \\
\text { > one cup }(\mathrm{n}=8)\end{array}$ & $\begin{array}{l}4(44.4) \\
26(86.7) \\
7(87.5)\end{array}$ & $\begin{array}{l}5(55.6) \\
4(13.3) \\
1(12.2)\end{array}$ & 7.81 & 0.020 \\
\hline $\begin{array}{l}\text { Amount of serving vegetables provided daily } \\
(\mathbf{n}=\mathbf{5 1}) \\
\text { Nothing }(n=6) \\
3 / 4 \text { cup }(n=13) \\
\text { One cup }(n=18) \\
\geq 11 / 2 \text { cups }(n=3)\end{array}$ & $\begin{array}{l}4(66.7) \\
10(76.9) \\
16(88.9) \\
3(100)\end{array}$ & $\begin{array}{l}2(33.3) \\
3(23.1) \\
2(11.1) \\
0(0.0)\end{array}$ & 2.47 & 0.481 \\
\hline $\begin{array}{l}\text { Having enough amount of water daily } \\
\text { Always }(n=44) \\
\text { Not always }(n=36)\end{array}$ & $\begin{array}{l}37(84.1) \\
25(69.4)\end{array}$ & $\begin{array}{l}7(15.9) \\
11(30.6)\end{array}$ & 2.44 & 0.119 \\
\hline
\end{tabular}

* p-value of Fischer exact test

Table 5:- Difference between children with functional constipation and those without regarding different possible outcomes

\begin{tabular}{|l|l|l|l|}
\hline Outcomes & Functional constipation & \multirow{2}{*}{ p-value } \\
\cline { 2 - 3 } & $\begin{array}{l}\text { No } \\
\mathrm{N}=62 \\
\mathrm{~N}(\%)\end{array}$ & $\begin{array}{l}\text { Yes } \\
\mathrm{N}=18 \\
\mathrm{~N}(\%)\end{array}$ & \\
\hline Abdominal pain $(\mathrm{n}=20)$ & $13(21.0)$ & $7(38.9)$ & $0.122 * *$ \\
\hline Anal fissure $(\mathrm{n}=2)$ & $0(0.0)$ & $2(11.1)$ & $0.008 \infty$ \\
\hline Urinary tract infection $(\mathrm{n}=3)$ & $2(3.2)$ & $1(5.6)$ & $0.540 \infty$ \\
\hline Urine incontinence $(\mathrm{n}=8)^{*}$ & $6(9.7)$ & $2(11.1)$ & $0.965 \infty$ \\
\hline Stool incontinence $(\mathrm{n}=4)^{*}$ & $2(3.2)$ & $2(11.1 \%)$ & $0.182 \infty$ \\
\hline
\end{tabular}

* Valid in 16 cases $\quad * *$ Chi-square test

$\infty$ Fischer exact test 


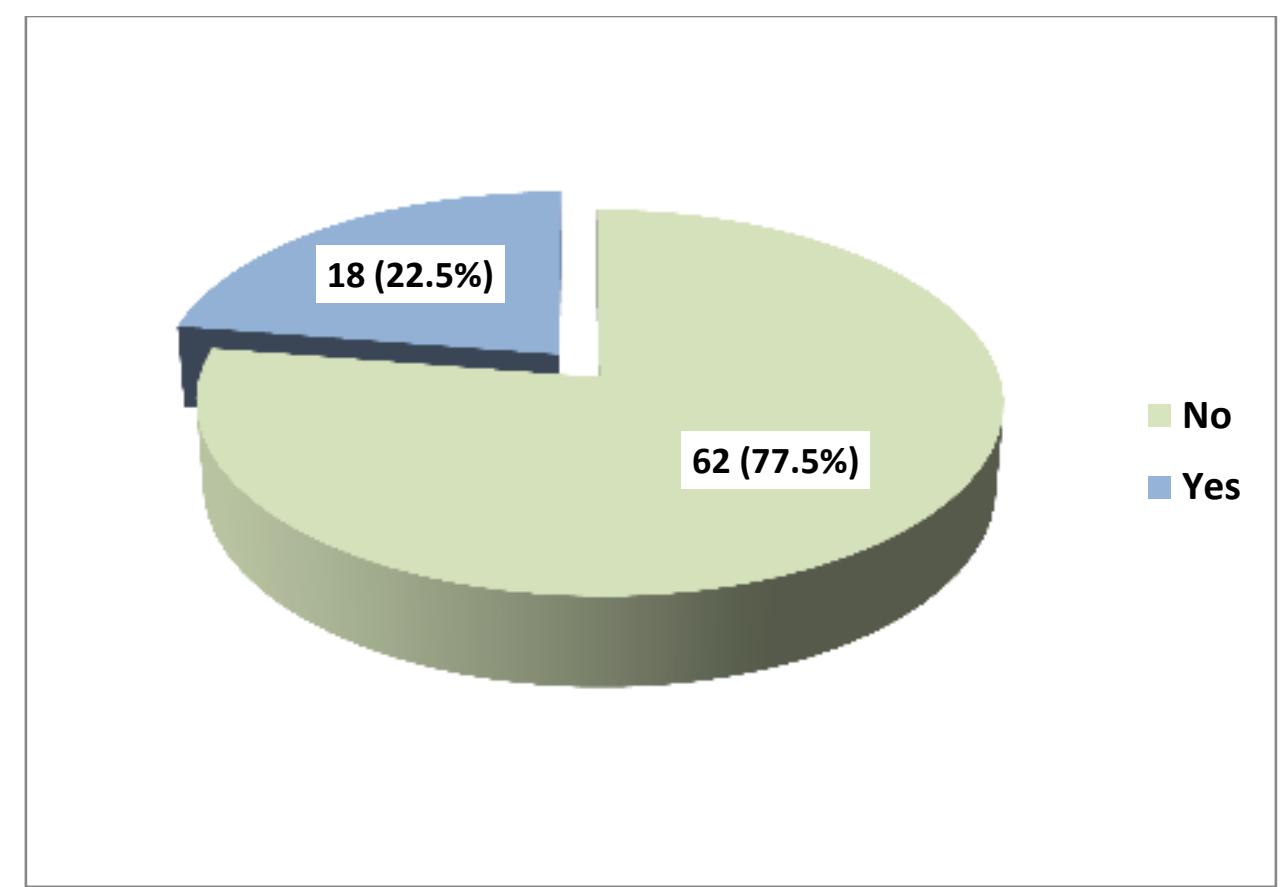

Figure (1):- Prevalence of functional constipation among children aged five years or less

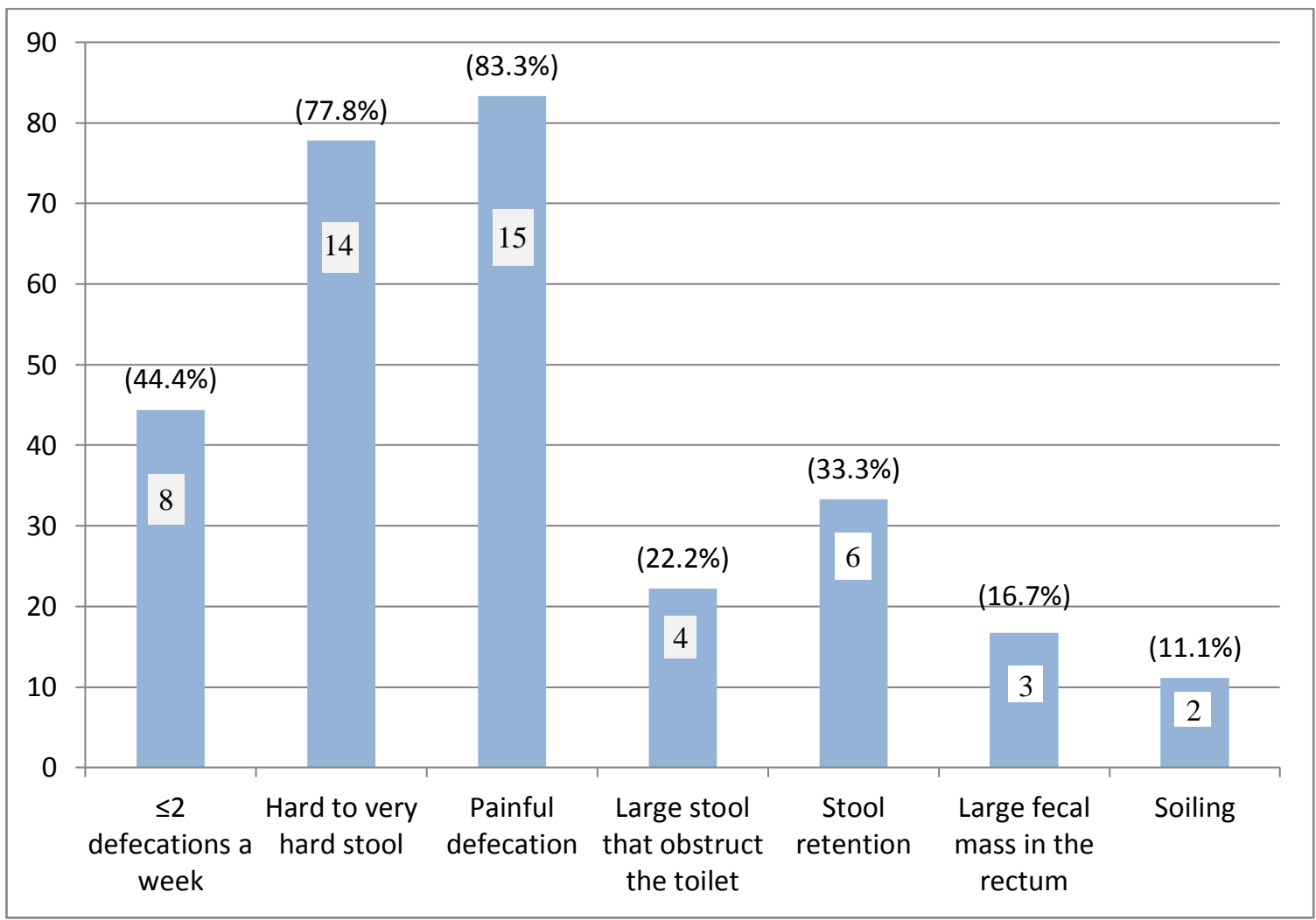

Figure (2):- Frequency of Rome III criteria among children with functional constipation $(n=18)$ 


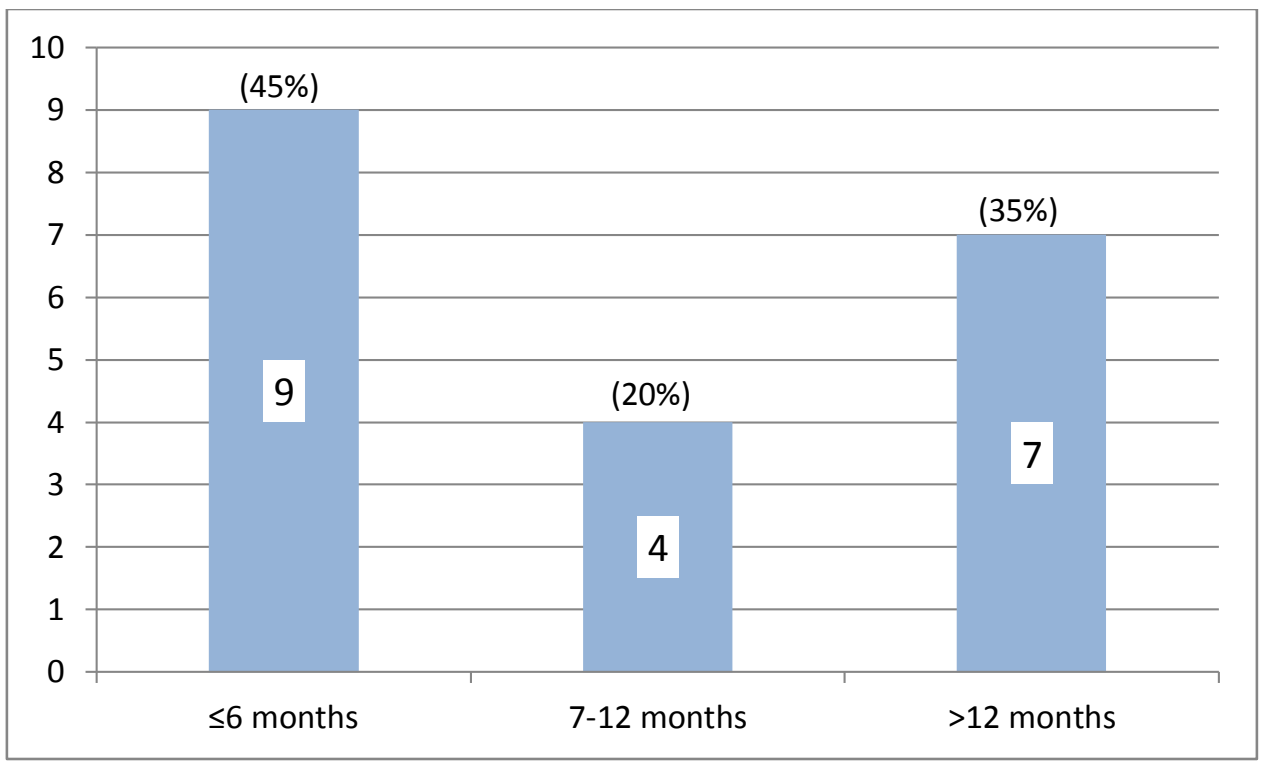

Figure (3):- Duration of abdominal pain among children $(\mathrm{n}=20)$

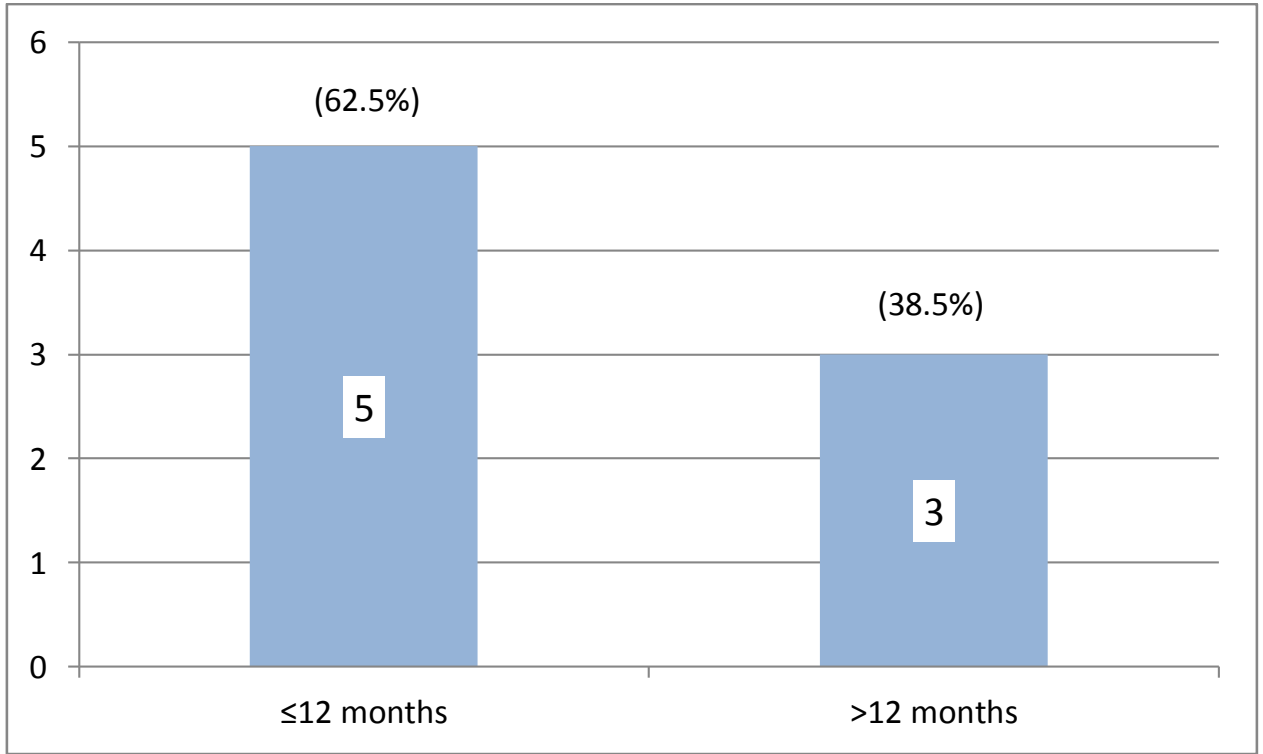

Figure (4):- Duration of urinary incontinence among children $(n=8)$

\section{Discussion:-}

The prevalence of functional constipation in the present study among children aged five years or less according to Rome III criteria was $22.5 \%$ (95\% CI 13.8 - 31.3). In another study carried out among 2-12 years children in Southern India, the prevalence of functional constipation was $13.6 \%{ }^{(10)}$. In Colombia, among infants up to 12 months, the prevalence was $16.1 \%$ whereas, among children from 13 to 48 months, the prevalence was $26.8 \%{ }^{(11)}$. In Northern areas of China, among children aged $4-14$ year, the prevalence of functional constipation was $4.7 \%$ with high prevalence in the age group $4-6$ years ${ }^{(12)}$. In USA, among children up to three years of age, $27.1 \%$ had at least one functional gastrointestinal disorder ${ }^{(13)}$.In Korea, among children ages at least 12 months the prevalence range was from $1.8 \%$ to $13.9 \%{ }^{(14)}$. The variation between prevalence rates of functional constipation among children in the aforementioned studies including ours could be mainly attributed to apparent difference in the age group of the studied population. Also, parent's recall could be a factor for variation in prevalence as the studies depended on parent's recall of their children history. 
The present study revealed no gender difference regarding the prevalence of functional constipation among children. This finding agrees with that reported in other studies carried out in Colombia, ${ }^{(11)} \mathrm{Korea}^{(15)}$ and USA ${ }^{(13)}$. However, it is not in line with other studies that showed gender predominance, in Southern India ${ }^{(10)}$, there was female predominance. In Northern China, the male to female ratio was 1.26: $1^{(12)}$. Male predominance was also reported from a study carried out in Romania ${ }^{(16)}$.

The mean age of children with functional constipation in this study was $23.6 \pm 18.4$ months. This is consistent with a study that was done in Romania ${ }^{(16)}$. In Colombia, the mean age of children was $19.3 \pm 15.3$ months $^{(11)}$. In Korea, the mean age was $54.5 \pm 15.1$ months ${ }^{(15)}$.In another study that was carried out in Korea, the mean age was $60.5 \pm 41.8$ months ${ }^{(14)}$ while in Iran the mean age was $5 \pm 3.12$ years ${ }^{(17)}$. It has been documented that in general population, nearly $75 \%$ of those who experienced functional constipation were between the ages 5-10 years. This may be because the parents were more concerned about bowel habits during younger age group and cease to be a priority to parents/child as they become older ${ }^{(10)}$.In the present study, there was no age difference regarding the prevalence of functional constipation. This finding is in line with a study that was done in Korea ${ }^{(15)}$.

In the current study, mother's level of education was not significantly associated with functional constipation and this is agree with Minkyu Park et al.'s study ${ }^{(15)}$. Also, the numbers of siblings was not significantly associated with functional constipation which is the same as Minkyu Park et al.'s finding ${ }^{(15)}$. However, Ashishchogle et al. reported that the prevalence of functional gastrointestinal disorders was high in children who were being the only child in the family ${ }^{(11)}$.

Regarding Rome III criteria of cases with functional constipation in the present study, the most reported symptoms were painful defecation (83.3\%) and hard to very hard stool (77.8\%). Stool frequency was 2 times or less per week among $44.4 \%$ and large stools that obstruct the toilet was reported among $22.2 \%$ of cases. Stool retention was reported by $38.9 \%$ of children whereas large fecal mass in the rectum was observed among $16.7 \%$ of them. Soiling (one to three times a month) was reported by $11.1 \%$ of children with functional constipation. It has been reported that clinical manifestation of functional constipation varies among different studies ${ }^{(17)}$. This difference may be due to a difference in diet and age group of children. In a study carried out by Dehghani et al. (2015) ${ }^{(17)}$, hard and large stool, painful defecation and retentive posture were observed among majority of cases $(93.7 \%, 92.3 \%$ and $91.9 \%$, respectively), soiling was reported by $33.8 \%$ of the cases, fecal mass and fecal impaction was present in $9.5 \%$, $59.9 \%$ of them, respectively. Chang et al., reported that $68 \%$ of their cases had a history of large fecal mass in the lower abdomen and $60 \%$ of them had hard stool consistency and painful defecation, while about one-third of the cases had a history of retentive posture, weekly soiling and stool frequency 2 times or less per week ${ }^{(14)}$. In another study carried out in Korea, painful defecation and hard stool was reported in $55.6 \%$ of cases, retentive posture was reported by $50 \%$ of the cases while $44.4 \%$ of them reported a stool frequency 2 times or less per week and a history of large fecal mass in the rectum, $38.9 \%$ had a history of large stool that obstruct the toilet and $27.8 \%$ reported soiling once per week or more ${ }^{(15)}$.

Regarding outcomes of functional constipation, the current study revealed that abdominal pain was reported by $38.9 \%$ of the children with functional constipation. In a study from Iran ${ }^{(17)}$, the abdominal pain was reported by $41.4 \%$ of children with functional constipation which is in line with our study, but Sujatha et al. reported lower frequency of abdominal pain among children with functional constipation $(29.7 \%)^{(10)}$. In this study, anal fissure was observed among $11.1 \%$ of cases and was significantly associated with functional constipation. Dehghani et al. reported $7.2 \%$ of children with functional constipation had anal fissure that was lower than the current study ${ }^{(17)}$. In the present study, urinary tract infection was reported by $5.6 \%$ of cases. Among toilet trained children, $11.1 \%$ had urinary and stool incontinence. Dehghani et al., found $5.8 \%$ of children with functional constipation had urinary tract infection ${ }^{(18)}$ which is agree with this study whereas, in a study carried out by Sujatha et al. ${ }^{(10)} 2.2 \%$ of children with functional constipation had urinary tract infection. Dehghani et al. reported 3.3\% and $22.5 \%$ of children with functional constipation had day time enuresis and night time enuresis, respectively ${ }^{(18)}$.

In the current study, although not always having enough amount of water daily was associated with higher rate of functional constipation, yet it did not reach statistical significance level. The same has been reported in another study carried out in Korea ${ }^{(14)}$. On the other hand, Minkyu Park et al. reported that $500 \mathrm{ml}$ or less of daily water intake was significantly associated with functional constipation ${ }^{(15)}$. 
In the present study, the non-intake of fruits and vegetables were higher among children with functional constipation, although it was significant only regarding fruits. This finding was in line with other studies. In Sujatha et al.'s study, there was a significant association between low fruits and vegetables intake and functional constipation (10). They reported that vegetables and fruits intake was low in most children and very low in constipated children. Minkyu Park et al. found that having 3 or fewer servings of fruits and vegetables per day was significantly associated with functional constipation ${ }^{(15)}$. In study carried out in Romania, the control group was consuming larger intake of fruits and vegetables than constipated group ${ }^{(16)}$.

In the present study, bottle feeding was significantly associated with functional constipation. In a study carrid out in Romania, cow's milk in the first year of life was significantly associated with functional constipation ${ }^{(16)}$. Minkuy et al. observed that in the constipated group of children, there was a significant association of breastfeeding for less than 6 months ${ }^{(15)}$. While, Sujatha et al. found in their study that there was no statistical significance for cow's milk ingestion in functional constipation.

Among important limitations of the study are time limitation and its cross-sectional design which proves only association and not causality between functional constipation and related factors. Also, the inclusion of cases from only one PHCC and within a specific age group might limit the generalizability of results over all children in Makkah. Finally, psycho-social factors were not included as possible risk factors for functional constipation. However, among strengths of the present study is the fact that all cases of functional constipation were identified by valid Rome III criteria. Furthermore, children were symptomatic as they came to well baby clinic for routine checkup or vaccination which limits selection bias.

\section{Conclusion:-}

Functional constipation is not uncommon gastrointestinal disturbance among children aged five years or less attending AlAdel primary health care center in Makkah as almost a quarter of children were affected according to Rome III criteria. Children of younger mothers, not consuming fruits, and on bottle feeding were more likely to have functional constipation compared to others.

Among affected children, stool frequency was two times or less per week among more than forty percent of them, hard to very hard stool and painful defecation were reported by the majority of cases and large stools that obstruct the toilet were reported among almost a quarter of cases.

Anal fissure was more significantly reported among children with functional constipation compared to those without functional constipation. Similarly, abdominal pain, urinary tract infection, urinary and stool incontinence were more reported among children with functional constipation than those without functional constipation; However, the differences were not statistically significant.

\section{Recommendations:-}

Based on the results and discussion of this study, the following are recommended:

1. Raising awareness of parents regarding symptoms and risk factors of functional constipation among their children; which emphasis on the importance of early recognition and management.

2. Educating mothers about the importance of breast feeding and daily fruit intake for their children to prevent functional constipation.

3. Better evaluation of the problem among children in Makkah through conducting multi-centric study including children with different presentations and risk factors.

4. Future studies are needed with larger samples and to confirm this study's findings on prevalence.

5. Future studies are needed to confirm this study's findings on the association of mother's age with having a child with functional constipation.

6. Longitudinal studies are also recommended to determine the actual causation rather than association between functional constipation and possible risk factors.

7. Inclusion of psycho-social factors in further studies as possible risk factors for functional constipation among children. 


\section{REFERENCES:-}

1. Constipation in infants and children [Internet]. [cited 2016 Jan 11]. Available from: http://www.uptodate.com/contents/constipation-in-infants-and-children-beyond-thebasics?source=search_result\&search $=$ constipation+in+children\&selectedTitle $=6 \sim 150$

2. Mcgrath KH, Caldwell P. Diagnostic Approach to Constipation in Children. 2010;1-19.

3. van den Berg MM, Benninga MA, Di Lorenzo C. Epidemiology of childhood constipation: a systematic review. Am J Gastroenterol [Internet]. 2006 Oct [cited 2015 Nov 27];101(10):2401-9. Available from: http://www.ncbi.nlm.nih.gov/pubmed/17032205

4. Functional constipation in infants and children: Clinical features and differential diagnosis [Internet]. [cited 2016 Jan 11]. Available from: http://www.uptodate.com/contents/functional-constipation-in-infants-andchildren-clinical-features-and-differentialdiagnosis?source=search_result\&search=constipation+in+children\&selectedTitle $=3 \sim 150$

5. Loening-Baucke V. Prevalence, symptoms and outcome of constipation in infants and toddlers. J Pediatr [Internet]. 2005 Mar [cited 2016 Jan 18];146(3):359-63. Available from: http://www.ncbi.nlm.nih.gov/pubmed/15756220

6. Borowitz SM, Cox DJ, Tam A, Ritterband LM, Sutphen JL, Penberthy JK. Precipitants of Constipation During Early Childhood. J Am Board Fam Med [Internet]. 2003 May 1 [cited 2016 Jan 11];16(3):213-8. Available from: http://www.jabfm.org/content/16/3/213.short

7. Journal of Pediatric Gastroenterology and Nutrition [Internet]. [cited 2016 Jan 11]. Available from: http://journals.lww.com/jpgn/Fulltext/1999/02000/Diet_and_Chronic_Constipation_in_Children_The.15

8. Youssef NN, Langseder AL, Verga BJ, Mones RL, Rosh JR. Chronic childhood constipation is associated with impaired quality of life: a case-controlled study. J Pediatr Gastroenterol Nutr. 2005;41(1):56-60.

9. Loening-Baucke V. Urinary Incontinence and Urinary Tract Infection and Their Resolution With Treatment of Chronic Constipation of Childhood. Pediatrics [Internet]. 1997 Aug 1 [cited 2015 Nov 6];100(2):228-32. Available from: http://pediatrics.aappublications.org/content/100/2/228.short

10. Sujatha B, Velayutham DR, Deivamani N, Bavanandam S. Normal Bowel Pattern in Children and Dietary and Other Precipitating Factors in Functional Constipation. J Clin Diagn Res [Internet]. 2015;9(6):SC12-5. Available from: /pmc/articles/PMC4525568/?report=abstract

11. Chogle A, Velasco-Benitez CA, Koppen IJ, Moreno JE, Ramírez Hernández CR, Saps M. A Population-Based Study on the Epidemiology of Functional Gastrointestinal Disorders in Young Children. J Pediatr [Internet]. 2016;179:139-143.e1. Available from: http://linkinghub.elsevier.com/retrieve/pii/S0022347616308782\%5Cnhttp://www.ncbi.nlm.nih.gov/pubmed/277 26867

12. Zhang S, Wang W, Qu R, Su P, Zhang S, Zhang H, et al. [Epidemiologic survey on the prevalence and distribution of childhood functional constipation in the northern areas of China: a population-based study]. Zhonghua Liu Xing Bing Xue Za Zhi [Internet]. 2010 Jul [cited 2017 Jul 30];31(7):751-4. Available from: http://www.ncbi.nlm.nih.gov/pubmed/21162836

13. Van Tilburg MAL, Hyman PE, Walker L, Rouster A, Palsson OS, Kim SM, et al. Prevalence of functional gastrointestinal disorders in infants and toddlers. J Pediatr [Internet]. 2015;166(3):684-9. Available from: http://dx.doi.org/10.1016/j.jpeds.2014.11.039

14. Chang SH, Park KY, Kang SK, Kang KS, Na SY, Yang HR, et al. Prevalence, clinical characteristics, and management of functional constipation at pediatric gastroenterology clinics. J Korean Med Sci. 2013;28(9):1356-61.

15. Park M, Bang YG, Cho KY. Risk Factors for Functional Constipation in Young Children Attending Daycare Centers. J Korean Med Sci. 2016;31(8):1262-5.

16. C O, S D, L T, N G, G S, G. C, et al. Some Risk Factors of Chronic Functional Constipation Identified in a Pediatric Population Sample from Romania. Gastroenterol Res Pract [Internet]. 2016;2016(vi):no pagination. Available

from: http://www.hindawi.com/journals/grp/\%0Ahttp://ovidsp.ovid.com/ovidweb.cgi?T=JS\&PAGE=reference\&D=e med18b\&NEWS $=$ N\&AN $=613626526$

17. Dehghani SM, Kulouee N, Honar N, Imanieh M-H, Haghighat M, Javaherizadeh H. Clinical Manifestations among Children with Chronic Functional Constipation. Middle East J Dig Dis [Internet]. 2015;7(1):31-5. Available from: /pmc/articles/PMC4293798/?report=abstract

18. Dehghani SM, Basiratnia M, Matin M, Hamidpour L, Haghighat M, Hadi Imanieh M. Urinary tract infection and enuresis in children with chronic functional constipation. Iran J Kidney Dis. 2013;7(5):363-6. 